\title{
Response of Alumina-Based Ceramic Thermoluminescence Detector to Charged Particles
}

\author{
Yusuke Koba, ${ }^{*}$ Weishan Chang, ${ }^{1}$ Kiyomitsu Shinsho, ${ }^{1}$ Shin Yanagisawa, ${ }^{1}$ \\ Genichro Wakabayashi, ${ }^{2}$ Kazuki Matsumoto, ${ }^{3}$ Hiroaki Ushiba,${ }^{3}$ and Takayuki Ando ${ }^{4}$ \\ Medical Exposure Research Project, National Institute of Radiological Sciences, \\ 4-9-1 Anagawa, Inage-ku, Chiba 263-8555, Japan \\ 'Division of Radiological Sciences, Faculty of Health Sciences, Tokyo Metropolitan University, \\ 7-2-10 Higashi-Ogu, Arakawa-ku, Tokyo 116-8551, Japan \\ ${ }^{2}$ Atomic Energy Research Institute, Kindai University, 3-4-1 Kowakae, Higashiosaka-shi, Osaka 577-8502, Japan \\ ${ }^{3}$ Chiyoda Technol Co., 2-16-2 Sotokanda, Chiyoda-ku, Tokyo 101-0021, Japan \\ ${ }^{4}$ Chiba Ceramic Mfg. Co., Ltd., 2-10-14 Inage-higashi, Inage-ku, Chiba 263-0031, Japan
}

(Received January 28, 2016; accepted May 18, 2016)

Keywords: alumina-based ceramics, TLD, charged particle, LET dependence

Ceramic thermoluminescence detectors (TLDs) are low-cost devices with high spatial resolution and very easy to use. The basic characteristics of alumina-based ceramic TLDs (Chiba Ceramic Mfg. Co., Ltd. A8) in response to X-ray and charged particle beams (H, He, C, Ne, Ar) have been reported in an effort to apply TLDs as a QA/QC tool for charged particle therapy. The glow curve has two peaks, and the main peak is located at $148{ }^{\circ} \mathrm{C}$ and $694 \mathrm{~nm}$. For each irradiation, four dose levels were given: $0.5,1.0,2.0$, and $5.0 \mathrm{~Gy}$ in water. The main peak showed good linearity and repeatability for X-rays. However, thermoluminescence efficiency decreased slightly with increasing irradiation dose with charged particle irradiation. The thermoluminescence efficiency of the main peak showed a very small dependence on linear energy transfer (LET) compared with common TLDs. This ceramic TLD may be applicable as a verification tool in a limited LET range such as proton therapy.

\section{Introduction}

Thermoluminescence detectors (TLDs) have been widely used for dosimetry in various fields. In 1972, Broadhead and Newman reported 2D X-ray imaging using $\mathrm{CdSO}_{4} \cdot{ }^{(1)}$ Since then, there have been many reports on 2D dosimetry using TLD. Nariyama et al., ${ }^{(2)}$ Shinsho et al., ${ }^{(3)}$ and Marczewska et al. ${ }^{(4-6)}$ measured the thermoluminescence (TL) distribution of TL sheets or TL pleats using charge-coupled device (CCD) cameras. These researchers predicted the use of TLDs as quality assurance (QA) / quality control (QC) tools in radiation therapy. In fact, 2D dosimetry using TL sheets in radiation therapy was reported in 1995.(6)

Charged particle therapies, such as proton and carbon therapy, have beome popular internationally as radiation modalities for cancer treatment. Verification of the irradiation field or dose distribution in charged particle therapy requires measurements with high spatial resolution, because these distributions are precipitous and complex. Measurement of dose distributions in

*Corresponding author: e-mail: koba.yusuke@qst.go.jp 
carbon therapy using plate TLD composed of $\mathrm{Li}_{3} \mathrm{~B}_{7} \mathrm{O}_{12}$ and synthetic resin has been carried out, but it was reported that the TL efficiency decreased crucially in high-LET regions. ${ }^{(7)}$

Recently, it has been reported that commercial alumina-based ceramic plates show good TL characteristics and are available for use in 2D dosimetry. ${ }^{(8)}$ This ceramic TLD is very easy to use, is low-cost, and has high spatial resolution. To use this ceramic TLD in charged particle therapy as a verification tool, we investigated the TL characteristics of this alumina-based ceramic TLD in response to charged particle beams.

\section{Materials and Methods}

\subsection{Alumina-based ceramic TLDs}

In this study, ceramics from Chiba Ceramic Mfg. Co., Ltd. were used as TLDs. Table 1 shows the composition of this ceramic TLD. Its size was $10 \times 10 \times 1 \mathrm{~mm}^{3}$. The glow curve of this TLD has a main peak at $694 \mathrm{~nm}$ due to the embedded $\mathrm{Cr}^{3+}$, which is paltry amount contained within the ceramic. ${ }^{(8)}$ Figure 1 shows a sample of the wavelength and temperature property of the ceramic TLD recorded with a multichannel spectroscope (HAMAMATSU PMA-12).

Table 1

Nominal composition of the alumina-based ceramic TLD (Chiba Ceramic Mfg. Co., Ltd. A8).

\begin{tabular}{lc}
\hline Ingredient & \% by weight \\
\hline $\mathrm{Al}_{2} \mathrm{O}_{3}$ & $>99.5$ \\
$\mathrm{SiO}_{2}$ & $<0.10$ \\
$\mathrm{Fe}_{2} \mathrm{O}_{3}$ & $<0.05$ \\
$\mathrm{Na}_{2} \mathrm{O}$ & $<0.10$ \\
\hline
\end{tabular}

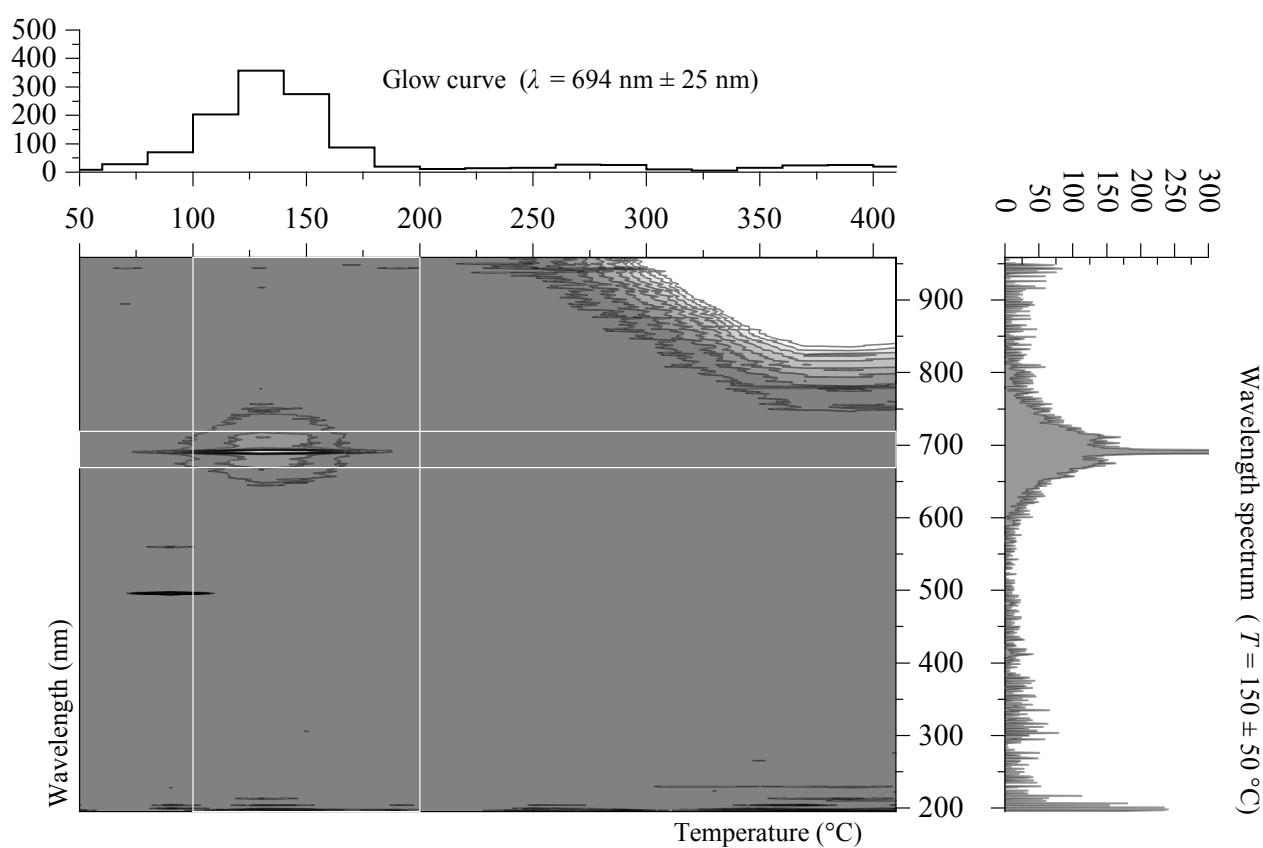

Fig. 1. Wavelength and temperature property of the ceramic TLD when it is irradiated by X-rays. 


\subsection{Irradiation beams}

Irradiation experiments with several charged particle beams were performed at the $\mathrm{BIO}$ course of the Heavy-Ion Medical Accelerator (HIMAC) at the National Institute of Radiological Sciences, Chiba, Japan. The beams were laterally broadened by a wobbling and scattering system to form a uniform field with a $10 \mathrm{~cm}$ diameter. ${ }^{(9)}$ Table 2 shows the irradiation beams used in this study. The LET in water was calculated by Geant4. ${ }^{(10)}$ The X-ray irradiation was carried out using a Varian CLINAC-21EX linear accelerator at $6 \mathrm{MV}$. For each irradiation, four dose levels were given: 0.5, 1.0, 2.0, and $5.0 \mathrm{~Gy}$ in water. This range simulates the predicted dose used in the charged particle therapy.

\subsection{Glow curve measurement}

The precise glow curve of the ceramic TLD was measured using a photon-counting unit (HAMAMATSU H11890-110) and a brass-plate-heater-connected programmable heat controller (Sakaguchi E.H VOC CORP. SCR-SHQ-A). Figure 2 shows the glow curves recorded from room temperature to $400{ }^{\circ} \mathrm{C}$ at a heating rate of $0.13^{\circ} \mathrm{C} / \mathrm{s}$ in air.

Table 2

Irradiation beams in this study.

\begin{tabular}{lcc}
\hline Particle & Energy $(\mathrm{MeV} / \mathrm{u})$ & LET in water $(\mathrm{keV} / \mu \mathrm{m})$ \\
\hline $\mathrm{H}$ & 160 & 0.5 \\
$\mathrm{He}$ & 150 & 2.0 \\
$\mathrm{C}$ & 290 & 13.2 \\
$\mathrm{Ne}$ & 400 & 29 \\
$\mathrm{Ar}$ & 500 & 86 \\
\hline
\end{tabular}

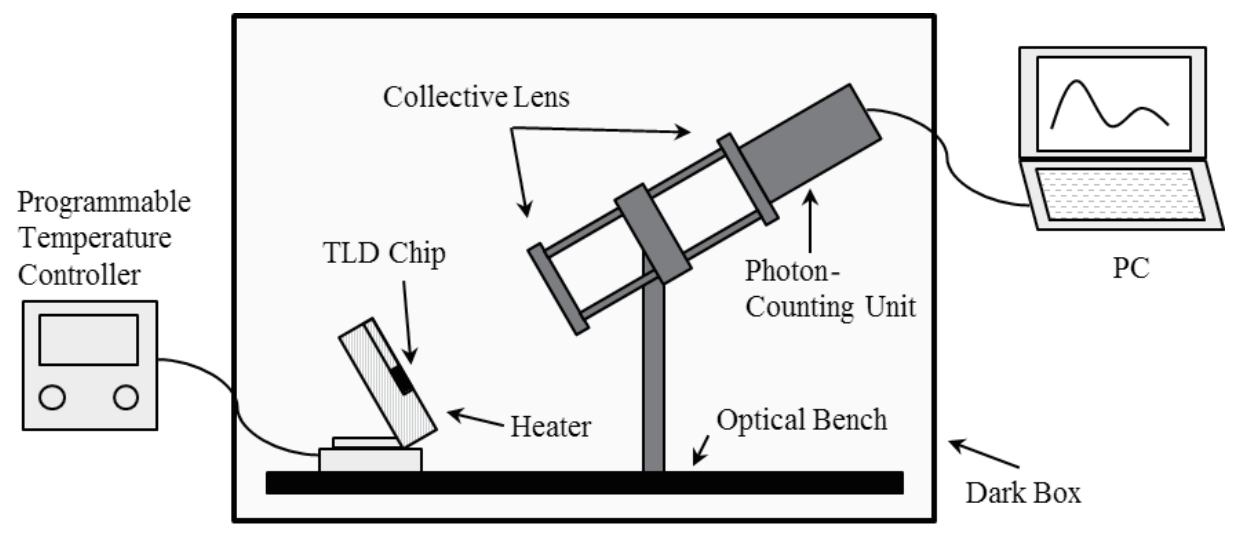

Fig. 2. Glow curve measurement system in this study. 


\section{Results and Discussion}

\subsection{Glow curve and dose linearity}

Figure 3 shows the precise glow curve of this alumina-based ceramic TLD. The peaks were located at $148{ }^{\circ} \mathrm{C}$ (main peak) and $285{ }^{\circ} \mathrm{C}$ (subpeak). The subpeak was affected by the thermal radiation of the heater. In this study, the main peak, which was not affected by the thermal radiation, was evaluated. The TL intensity was evaluated over a range of $10{ }^{\circ} \mathrm{C}$ centered on the main peak. Figure 4 shows the dose response of this ceramic TLD to several irradiations. The TL intensity was normalized using the following equation:

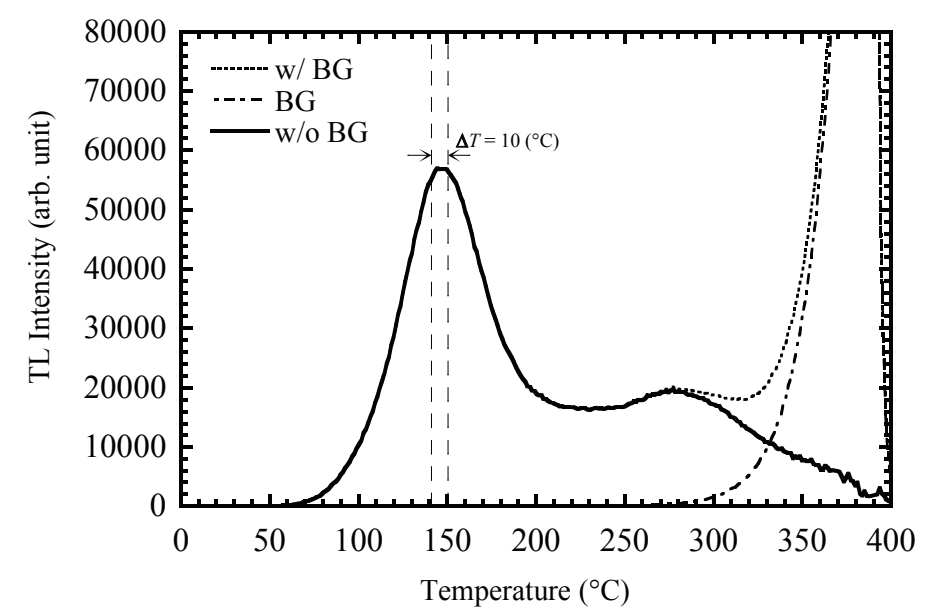

Fig. 3. Glow curve of the alumina-based ceramic TLD.

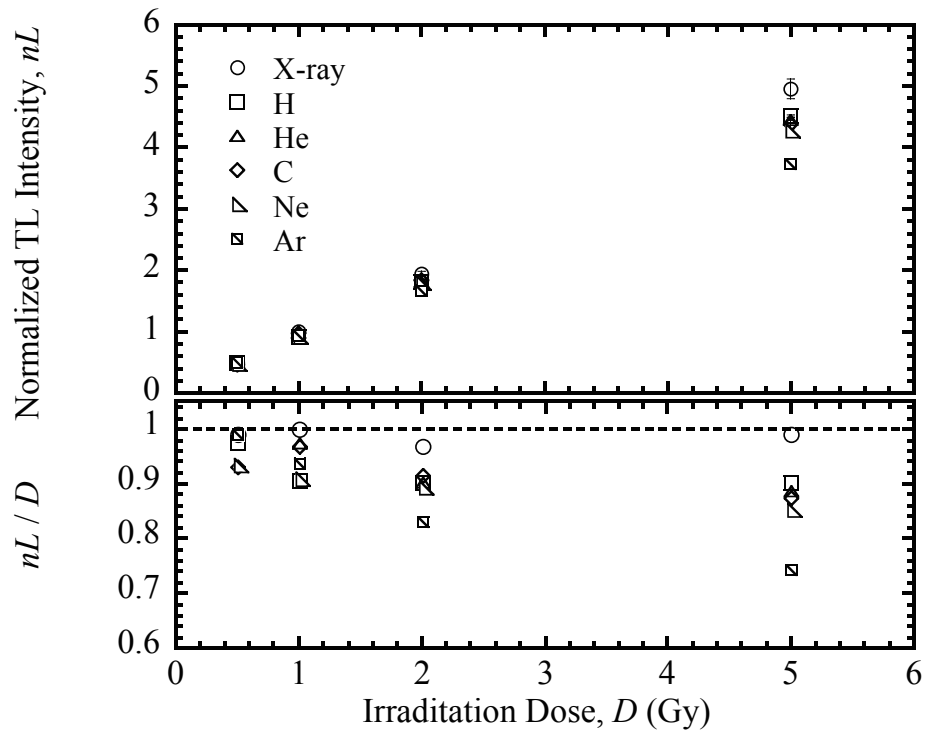

Fig. 4. Dose responses to X-ray and charged particles. TL intensity was normalized at 1 Gy for X-rays. 


$$
n L(D)=\frac{L(D)}{L_{\mathrm{X} \text {-ray }}(1 \mathrm{~Gy})},
$$

where $D$ is the irradiation dose, $L(D)$ is the TL intensity for an irradiation of $D$ Gy, and $n L(D)$ is the normalized TL intensity. For X-rays, dose linearity and repeatability were comparatively good. However, for charged particles, the TL efficiency $n L / D$ decreased slightly with increasing irradiation dose. This dose response showed a greater tendency with particles of higher atomic number.

\subsection{LET dependence}

Table 3 and Fig. 5 show the LET dependence of the TL efficiency $n L(D)$ of the main peak. When the irradiation was lower than $1 \mathrm{~Gy}$, the LET dependence was very small (less than $10 \%$ ). In the range from 0.1 to $30 \mathrm{keV} / \mathrm{mm}$, the LET dependence was less than $15 \%$ with 15 Gy irradiation. The TL efficiency of the peak located at $148{ }^{\circ} \mathrm{C}$ showed a small LET dependence as compared

Table 3

TL efficiency $n L D$ of alumina-based ceramic TLD.

\begin{tabular}{lcccccc}
\hline & \multirow{2}{*}{ LET $(\mathrm{keV} / \mu \mathrm{m})$} & $0.5 \mathrm{~Gy}$ & $1 \mathrm{~Gy}$ & $2 \mathrm{~Gy}$ & $5 \mathrm{~Gy}$ & Average \\
\hline $\mathrm{X}$-ray & 0.2 & 0.99 & 1.00 & 0.97 & 0.99 & 0.99 \\
$\mathrm{H}$ & 0.5 & 0.98 & 0.91 & 0.90 & 0.90 & 0.92 \\
$\mathrm{He}$ & 2.0 & 0.99 & 0.98 & 0.90 & 0.89 & 0.94 \\
$\mathrm{C}$ & 13.2 & 0.93 & 0.97 & 0.92 & 0.87 & 0.92 \\
$\mathrm{Ne}$ & 29 & 0.94 & 0.91 & 0.89 & 0.85 & 0.90 \\
$\mathrm{Ar}$ & 86 & 0.99 & 0.94 & 0.83 & 0.74 & 0.88 \\
\hline
\end{tabular}

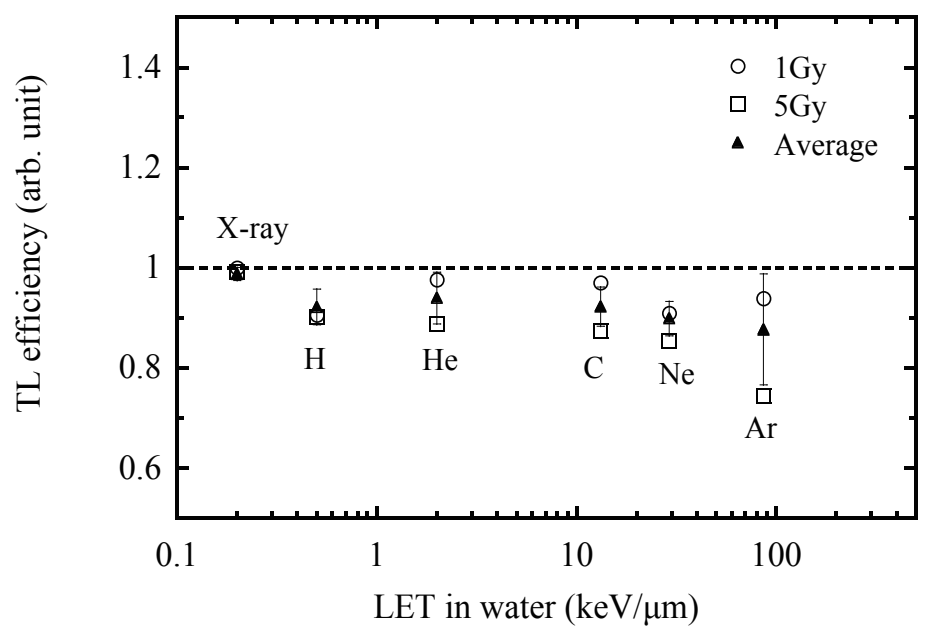

Fig. 5. LET dependence of TL efficiency $n L D$. 
with common TLDs. ${ }^{(11)}$ In Ar irradiation, the TL efficiency was $>74 \%$ at $86 \mathrm{keV} / \mathrm{mm}$. Berger and Hajek reported an overview of the TL efficiency of several common TLDs. ${ }^{(11)}$ According to their report, the TL efficiency of most TLDs in the range of $10-100 \mathrm{keV} / \mathrm{mm}$ was less than $50 \%$. For dosimetry in charged particle therapy, the use of solid-state detectors such as TLDs has been generally avoided, owing to the large dependence on LET. The ceramic TLD may be applicable as a verification tool in a limited LET range, such as that of proton therapy, because the measurement system using this ceramic TLD provides $2 \mathrm{D}$ dose distribution in a very simple manner. ${ }^{\left({ }^{8}\right.}$

\section{Conclusions}

In this study, the basic characteristics of an alumina-based ceramic TLD (Chiba Ceramic Mfg. Co., Ltd. A8) in response to X-rays and charged particle beams were determined. The glow curve had two peaks, and the main peak located at $148{ }^{\circ} \mathrm{C}$ showed good linearity and repeatability in response to X-ray. However, the TL efficiency decreased slightly with increasing irradiation dose with charged particle irradiation. The TL efficiency of the main peak showed a very small dependence on LET compared with common TLDs. This ceramic TLD may be applicable as a verification tool in a limited LET range, such as that of proton therapy.

\section{Acknowledgements}

This work was performed as a Research Project with Heavy Ions at the NIRS-HIMAC. We are deeply grateful to Daichi Sasaki and Chie Koyama of Tokyo Metropolitan University. This work was partially supported by the Cooperative Research Project of the Research Institute of Electronics, Shizuoka University.

\section{References}

1 P. Broadhead and G.A. Newman: J. Phys., E. 5 (1972) 024.

2 N. Nariyama, A. Konnai, S. Ohnishi, N. Odano, A. Yamaji, N. Ozasa, and Y. Ishikawa: Radiat. Prot. Dosimetry 120 (2006) 136.

3 K. Shinsho, Y. Tomizawa, H. Horikawa, S. Miyajima, H. Saitoh, and A. Urushiyama: Radiat. Meas. 46 (2011) 1912.

4 B. Marczewska, P. Bilski, M. Nesladek, P. Olko, M. Rębisz, and M. P. R. Waligórski: Phys. Status Solidi Appl. Res. 193 (2002) 470.

5 B. Marczewska, P. Bilski, L. Czopyk, P. Olko, M. P. R. Waligórski, and S. Zapotoczny: Radiat. Prot. Dosimetry 120 (2006) 129.

6 K. Iwata, H. Yoshimura, T. Tamada, H. Ohishi, H. Uchida, M. Nakagawa, K. Utsunomiya, I. Yamamoto, and T. Wada: Cancer Detect Prev. 19 (1995) 367.

7 Y. Koba, S. Fukuda, K. Shinsho, G. Wakabayashi, and S. Tamatsu: J. Korean Phys. Soc. 63 (2013) 1432.

8 K. Shinsho, Y. Kawaji, S. Yanagisawa, K. Otsubo, Y. Koba, G. Wakabayashi, K. Matsumoto, and H. Ushiba: Appl. Radiat. Isot. 111 (2016) 117.

9 M. Torikoshi, S. Minohara, N. Kanematsu, M. Komori, M. Kanazawa, K. Noda, N. Miyahara, H. Itoh, M. Endo, and T. Kanai: J. Radiat. Res. 48, Suppl. A (2007) A15.

10 S. Agostinelli, J. Allison, and K. Amako: Nucl. Instrum. Methods Phys. Res., Sect. A. 506 (2003) 250.

11 T. Berger and M. Hajek: Radiat. Meas. 43 (2008) 146. 